\title{
REDUCED SURVIVAL IN WOMEN AFTER VALVE SURGERY FOR AORTIC REGURGITATION: EFFECT OF AORTIC ENLARGEMENT AND LATE AORTIC RUPTURE
}

Monica L. McDonald, MD

Nicholas G. Smedira, MD

Eugene H. Blackstone, $\mathrm{MD}^{\mathrm{a}, \mathrm{b}}$

Richard A. Grimm, DO ${ }^{c}$

Bruce W. Lytle, MD

Delos M. Cosgrove, $\mathrm{MD}^{\mathrm{a}}$
Objective: We sought to investigate the relationship of female sex, aortic pathology, and left ventricular function to outcome after an operation for aortic regurgitation.

Methods: One hundred nine women underwent aortic valve replacement (n =92) or repair $(n=17)$ for pure aortic regurgitation between 1985 and 1996 . Mean follow-up was $5.7 \pm 2.6$ years. New York Heart Association functional class III-IV symptoms were present in 70 patients, whereas left ventricular function was normal in 60 patients. Ascending aortic diameter in $97 \%$ exceeded the 90th percentile for a size-matched healthy population. A concomitant aortic operation was performed by means of root replacement in 31 patients and by means of interposition graft in 28 patients. Of 50 patients undergoing isolated valve procedures, 19 had aortas of $4.0 \mathrm{~cm}$ or larger.

Results: At 5 and 10 years, survival was $78 \%$ and $44 \%$, respectively. Fatal aortic rupture occurred in 13 patients, and 2 others underwent emergency operations for impending aortic rupture, for a total of 15 late aortic events. Freedom from aortic events was $87 \%$ and $76 \%$ at 5 and 10 years, respectively. Risk factors for aortic events were older age $(P=.07)$ and increasing ascending aortic diameter indexed to body surface area $(P=.03)$ in women who had not undergone replacement of the ascending aorta. Rupture location was at the ascending aorta in $71 \%$ without ascending replacement and the descending aorta in $62 \%$ with ascending grafts.

Conclusion: In women, late survival after an operation for aortic regurgitation is importantly decreased by coexisting aortic pathology with subsequent aortic rupture. Aortic replacement at the time of a valve operation should be considered on the basis of indexed aortic size. (J Thorac Cardiovasc Surg 2000;119:1205-15)
$T_{\text {atios }}^{\text {he }}$ he association of sex with outcomes after cardiac operations is receiving greater attention. Recent publications have highlighted the worse prognosis for women after coronary artery bypass grafting and their increased

From the Department of Thoracic and Cardiovascular Surgery, Department of Biostatistics and Epidemiology, ${ }^{\mathrm{b}}$ Department of Cardiology, ${ }^{\mathrm{c}}$ The Cleveland Clinic Foundation, Cleveland, Ohio.

Read at the Seventy-ninth Annual Meeting of The American Association for Thoracic Surgery, New Orleans, La, April 18-21, 1999.

Received for publication April 22, 1999; revisions requested Sept 29, 1999; revisions received Jan 27, 2000; accepted for publication Feb 3, 2000.

Address for reprints: Nicholas G. Smedira, MD, Department of Thoracic and Cardiovascular Surgery, 9500 Euclid Ave, Desk F25, Cleveland, OH 44195 (E-mail: smedirn@ccf.org).

Copyright () 2000 by The American Association for Thoracic Surgery

$0022-5223 / 2000 \$ 12.00+0 \quad \mathbf{1 2 / 6 / 1 0 6 3 2 9}$

doi: $10.1067 / \mathrm{mtc} .2000 .106329$ incidence of rejection after cardiac transplantation., ${ }^{1,2}$ Little information is available to determine whether sex influences the indications for and the outcomes after a heart valve operation. Klodas and colleagues ${ }^{3}$ from the Mayo Clinic reported increased late mortality after aortic valve operations for women with aortic regurgitation. ${ }^{3}$ Female sex persisted as a risk factor despite a sequence of multivariable analyses that took into account patient size, left ventricular dimension, and concomitant ascending aortic aneurysm repair. More women than men presented with aortic pathology, and the mechanism of late death differed in men and women: a larger proportion of the women who died did so as a result of aortic rupture. The cause of this excess mortality and the higher occurrence of late aortic rupture is unknown. Therefore, we reviewed the outcome and mechanism of death in women undergoing aortic valve operations for pure aortic regurgitation, specifically focusing on the aorta to elucidate its relationship to outcome. 


\section{Methods}

Patients. Using the prospective Cardiovascular Information Registry (CVIR), 109 women were identified who had undergone an operation for pure native aortic valve regurgitation between January 1, 1985, and January 1, 1996, at The Cleveland Clinic Foundation. This excluded women with associated important aortic valve stenosis, concomitant mitral or tricuspid valve procedures, Marfan's syndrome with evidence of dissection, aortic dissection presenting with aortic regurgitation, and endocarditis.

Data. CVIR personnel prospectively abstracted the patients' clinical records. These prospective data were supplemented by thorough review of all clinical records and by quantitative echocardiographic review (see below).

The majority of the women had moderately severe (44 [40\%]) or severe (47 [43\%]) aortic regurgitation, although 18 $(17 \%)$ had only moderate regurgitation. Pathology of the aortic valve itself was not remarked upon in the records of 33 $(30 \%)$ patients, and these may represent structurally normal valves. It was stated explicitly that the valve was structurally normal in $58(53 \%)$. In a few the aorta was bicuspid (7 [6\%]), prolapsing $(6[6 \%])$, or had restricted motion (without stenosis, $5[5 \%])$.

The reason for operation was symptomatic aortic regurgitation in $46(42 \%)$, aneurysmal disease in $26(24 \%)$, and the combination of symptomatic regurgitation and aneurysmal disease in $37(34 \%)$ patients. More than half the women $(58 \%)$ came to operation for aortic regurgitation associated with aneurysmal disease. This was treated by ascending aortic aneurysm repair in 59, either by root replacement (composite graft or allograft, $n=31$ ) or by the interposition graft technique $(n=28)$. No valve-sparing operations were performed.

The women ranged in age from 18 to 79 years with a median age of 67 years. They weighed between 46 and $115 \mathrm{~kg}$, with $90 \%$ weighing less than $81 \mathrm{~kg}$. Their body surface area (BSA) ranged from $1.43 \mathrm{~m}^{2}$ to $2.28 \mathrm{~m}^{2}$, with a median of 1.68 $\mathrm{m}^{2}$. Cardiac and noncardiac comorbidities of these women are described in Appendix Table I.

Echocardiographic measurements. Biplane and multiplane transesophageal echocardiography was performed preoperatively in 106 patients by means of a Hewlett-Packard ultrasonographic system with a 5-MHz biplane or multiplane transesophageal echocardiography transducer. With the aid of a plane orthogonal to the aortic short axis, standard diameter measurements were made at the aortic anulus, sinus of Valsalva, sinotubular junction, mid ascending aorta at the level of the right pulmonary artery, and the proximal descending aorta. ${ }^{4}$ The distribution of sizes of each of these structures is given in Appendix Table II.

Because the size of the normal aorta varies according to the size of the person, the measurements were also expressed as centimeters per square meter BSA, the indexed aortic size. For illustration, the distribution of the size of the ascending aorta indexed to body size is presented in Fig 1. In this figure we have also presented for comparison the mean predicted aortic diameter of a size-matched young female population. ${ }^{5}$
There is a known age-related increase in size of the aorta that we deliberately did not take into account in making these mean normal predictions because this relation may represent degeneration and not normality. ${ }^{6}$ In addition, we have calculated the $\mathrm{Z}$-value for the observed size of the ascending aorta on the basis of these normal sizes, which is also shown in Appendix Table II. The Z-value is the number of SDs above or below the mean normal value on the basis of the variability of normal young subjects. ${ }^{6}$

Follow-up. The patients were followed up at 2-year intervals through the CVIR. In addition, the patients were followed up cross-sectionally in September 1997. Two patients could not be traced in 1997, one foreign patient lost to followup 4 months after the operation and one other lost to followup 2.9 years after the operation. Mean follow-up among survivors was $5.7 \pm 2.6(\mathrm{SD})$ years (median, 5.6 years), ranging from 4.2 months to 10.5 years. Seventy-five percent of patients had follow-ups longer than 3.2 years and $25 \%$ longer than 7.8 years.

Outcome events. The outcomes for this study were (1) death from all causes and (2) an aortic event. Each death was reviewed, and a search was made for death certificates and other medical documents concerning the circumstances of the death. This yielded a minimum number of women dying of reported aortic rupture.

We defined an aortic event as occurring if the patient died of aortic rupture or required an operation on the thoracic aorta after aortic valve repair or replacement to prevent rupture. One woman was reoperated on for a pseudoaneurysm of the left coronary artery after a Bentall operation, and this was not considered an aortic event. Because of the limited number of autopsies performed, the diagnosis of rupture was based on clinical and radiographic results and discussions with families and physicians. An attempt was made to determine the site of aortic rupture from all available data; because of the limitation cited above and the limited number of reoperations, the designated site of the aortic problem is only the likely site and not the definitive site.

\section{Data analysis}

Risk-unadjusted analyses. Nonparametric estimates of survival and freedom from aortic rupture or repair were obtained by the method of Kaplan and Meier. ${ }^{7}$ A parametric method was used to resolve the number of hazard phases, identify the shape of the hazard function, and estimate its parameters. ${ }^{8}$ The duration of the two hazard phases identified in this study was across all time, but the early hazard phase dominated risk over the first year after operation. This was determined analytically from the data and not arbitrarily.

In addition, the magnitude of effect of aortic events on overall survival was estimated by censoring patients at the time of aortic rupture or repair (an aortic event) to obtain survival were aortic events not to occur. This analysis uses the theory of competing risks (multiple decrement tables). ${ }^{8-11}$ To accomplish this, at any time after operation, patients were placed in one of three mutually exclusive categories: (1) those still alive without an aortic event (so-called event-free survival), (2) those dying before an aortic event, and (3) those 


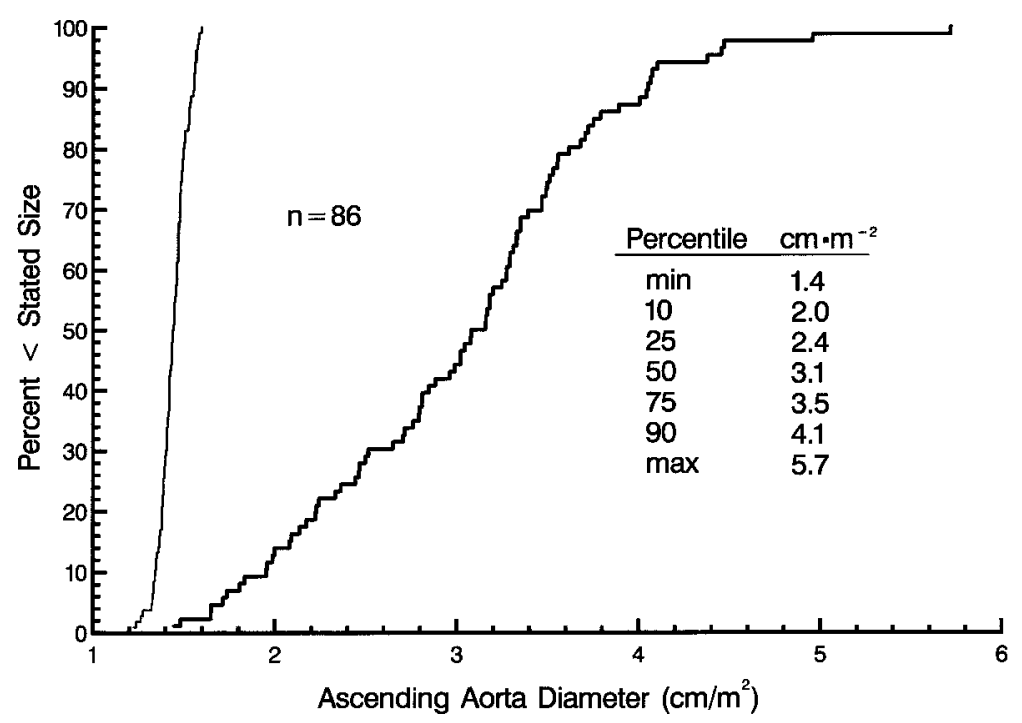

Fig 1. Cumulative frequency distribution of ascending aorta diameter indexed to BSA measured from the preoperative echocardiogram. Superimposed on the plot is the distribution of predicted mean normal size of the ascending aorta diameter indexed to BSA for young adults.

experiencing an aortic event. The common interval used for analysis was the earliest occurrence of death, an aortic event, or end of follow-up.

Multivariable analyses. The potential risk factors (variables) for death, aortic event (aortic rupture or repair), and death before an aortic event were organized for entry into the analyses as shown in Appendix Table III.

For general conduct of the multivariable analyses, exploratory analysis included correlation analysis, stratified life table analyses, and decile risk analysis of ordinal and continuous variables to determine possible transformations of scale (calibration). A directed technique of entry of variables into the multivariable risk factor model was then used. ${ }^{12}$ Extensive analysis was made of possible interactions, concentrating specifically on interactions with repair of the aorta. Noninformative imputation of missing values used the mean of values present in the data set; in addition, an indicator variable was created to assess and adjust for possible differences between patients with and without missing values for a variable. The $P$ value criterion for retention of variables in the final model was .1.

Exploration of the influence of risk factors in the parametric multivariable analysis was performed by constructing nomograms representing the solution of the parametric equation for specific supplied values of each factor.

The relationship of indexed size of the ascending aorta to the same variables incorporated into other multivariable analyses, except for other aortic structures, was conducted with the use of multiple linear regression.

Presentation. Regression coefficients are presented plus or minus one SE. We do not present hazard ratios because the hazard functions were not found to be proportionate across time; thus, nonproportional hazards methods were used.

Life tables and parametric estimates of the survivorship and hazard functions are presented with asymmetric confidence limits (CL) equivalent in width to one SE (68\%).

\section{Results}

Death. Thirty-five women died after the operation. Survival was $98 \%, 92 \%, 78 \%$, and $44 \%$ at 30 days and 1, 5, and 10 years of follow-up, respectively (Fig 2). Fourteen of the 35 deaths were associated with aortic rupture or occurred during emergency repair of a rupturing aorta (Table I). One other patient, who lived, required an emergency operation of the thoracic aorta.

Survival before an aortic event was $98 \%, 95 \%, 86 \%$, and $60 \%$ at 30 days and 1, 5, and 10 years of followup, respectively. The effect on survival by an aortic event is quantified in Fig 2. Even after accounting for deaths from aortic events, an age- and sex-matched population was predicted to survive longer than women after aortic valve replacement.

Risk factors for death included older age at operation, a history of smoking, a preoperative history of atrial fibrillation, and worse left ventricular dysfunction (Table II). Importantly, concomitant aortic replacement was not associated with increased risk, and specifically use of a composite valve and graft (Bentall operation) or aortic allograft as an aortic root replacement was associated with more favorable late survival. The strength and certainty of these factors differed 


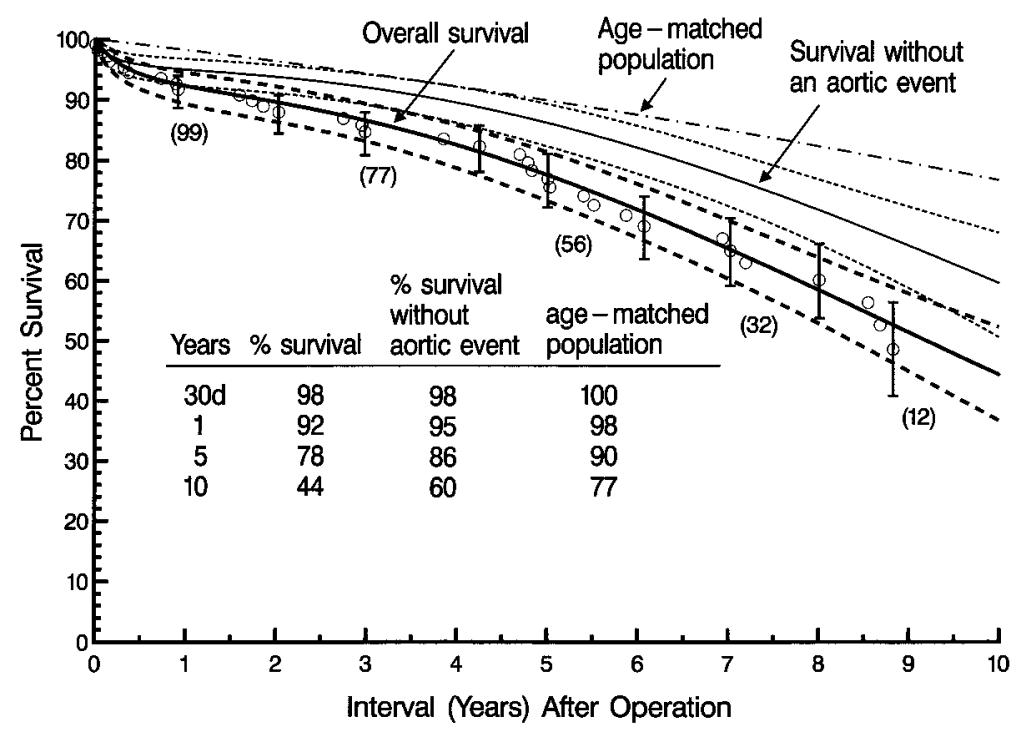

Fig 2. Survival after aortic valve replacement or repair. These depictions are compared: overall survival, survival before an aortic event (competing risks analyses, see "Methods" section), and the age-sex-general population life table. Overall survival: Each circle indicates a death positioned along the vertical axis by the nonparametric Kaplan-Meier method. Vertical bars are asymmetric confidence intervals equivalent to one SE. Numbers in parentheses represent the number of patients remaining at risk beyond that time point. The heavy smooth line and its confidence intervals represent the parametric survival estimates. Survival before an aortic event: The lighter smooth line and its confidence intervals represent survival were no aortic events to have occurred. Population life table: The dash-dot-dash line is the survival of women matched for age in the general population.

Table I. Circumstances of death

\begin{tabular}{|c|c|}
\hline Circumstance & No. \\
\hline In hospital & 2 \\
\hline Acute cardiac failure & 1 \\
\hline Pulmonary embolus & 1 \\
\hline Death from aortic events & 14 \\
\hline Rupture & 13 \\
\hline During an operation for impending rupture & 1 \\
\hline Congestive heart failure & 8 \\
\hline Cancer & 2 \\
\hline Renal failure & 2 \\
\hline Thrombosis of coronary artery & 1 \\
\hline Endocarditis & 1 \\
\hline Stroke & 1 \\
\hline Liver failure & 1 \\
\hline Hemorrhagic gastritis & 1 \\
\hline Uncertain & 2 \\
\hline Total & 35 \\
\hline
\end{tabular}

somewhat for all deaths and for deaths before an aortic event. Each of these risk factors is illustrated by univariable stratified life tables in Appendix Table IV. A relation between the size of aortic structures and overall death was masked by background deaths from various causes and by the aortic repair variable $(P>.2)$.
Aortic rupture or repair (aortic events). Fifteen women experienced either fatal aortic rupture $(n=13)$ or underwent emergency operation for prevention of aortic rupture $(\mathrm{n}=2)$. Freedom from an aortic event was $97 \%, 87 \%$, and $76 \%$ at 1,5 , and 10 years of follow-up, respectively. The incidence of an aortic event was constant across time at $2.7 \%$ per patient-year (CL, $2.1 \%-3.5 \%$ ).

Two risk factors were found for aortic events. Older women were at higher risk (constant hazard coefficient, $0.054 \pm 0.030 ; P=.07)$, as were women who had not undergone aortic replacement and had a larger ascending aorta ([1/indexed ascending aortic size], $-11.6 \pm$ $5.3 ; P=.03)$. No patient with an ascending aortic size of less than $3.5 \mathrm{~cm}$ experienced an aortic event in this study. However, the strongest association was not with absolute ascending aortic size but with the size of the aorta indexed to the size of the patient. The interrelation of these two factors in women not undergoing aortic replacement at the initial operation is illustrated by the nomogram in Fig 3. The figure illustrates that the older the patient, the more dangerous is a given degree of ascending aortic enlargement.

Aortic size. Compared with sex-matched control aortas, $90 \%$ of the aortic dimensions measured in this 


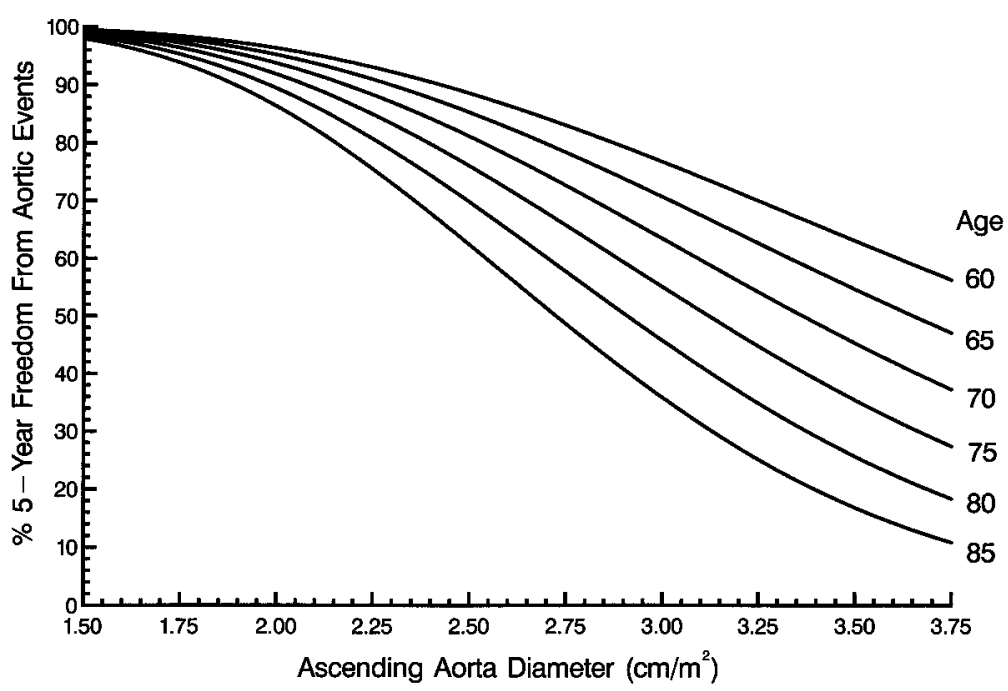

Fig 3. Nomogram from the multivariable analysis of aortic events. The depiction is freedom from the event at 5 years postoperatively according to the size of the ascending aorta indexed to BSA (horizontal axis) and the age of the patient at the original aortic valve operation.

Table II. Incremental risk factors for all deaths and deaths before an aortic event

\begin{tabular}{|c|c|c|c|c|}
\hline \multirow[b]{2}{*}{ Incremental risk factors } & \multicolumn{2}{|c|}{ All deaths } & \multicolumn{2}{|c|}{ Death before an aortic event } \\
\hline & Coefficient $\pm S D$ & $\mathrm{P}$ value & Coefficient $\pm S D$ & $\mathrm{P}$ value \\
\hline \multicolumn{5}{|l|}{ Early hazard phase } \\
\hline History of smoking & $2.1 \pm 1.03$ & .04 & $1.67 \pm 0.86$ & .05 \\
\hline \multicolumn{5}{|l|}{ Late hazard phase } \\
\hline Older age & $0.055 \pm 0.022$ & .01 & $0.042 \pm 0.027$ & .12 \\
\hline History of smoking & $0.74 \pm 0.56$ & .19 & $2.0 \pm 0.91$ & .03 \\
\hline Preoperative atrial fibrillation & $1.04 \pm 0.52$ & .05 & $1.60 \pm 0.76$ & .03 \\
\hline Worse left ventricular function & $0.66 \pm 0.27$ & .01 & $1.41 \pm 0.44$ & .001 \\
\hline Aortic root replacement* if ascending aneurysm repair & $-1.83 \pm 0.81$ & .02 & $-3.1 \pm 1.31$ & .02 \\
\hline
\end{tabular}

*Decreased risk (negative coefficient).

study had Z-values of greater than 2.2, with over 50\% greater than 9.5 (Appendix Table II). Despite this, there was heterogeneity as to the threshold for replacement of the aorta (Fig 4). This permitted us to assess the effect of nonreplacement of the aorta. Thus, of the patients whose aortas (anulus to distal ascending) were measured, at least 19 of 47 had a diameter greater than or equal to $4.0 \mathrm{~cm}$ and underwent isolated aortic valve replacement. In 6 patients the diameter was greater than $5.0 \mathrm{~cm}$. Among these 19 women, 6 experienced an aortic event (32\%), and 3 of these were among the 6 women with an aortic size greater than $5 \mathrm{~cm}(50 \%)$. In the 28 patients with aortas greater than or equal to 4.0 $\mathrm{cm}$ who underwent interposition grafting, $6(21 \%)$ experienced an aortic event. For those with valved con- duit or homograft replacement of the aorta and measured ascending aortas greater than or equal to $4.0 \mathrm{~cm}$ $(\mathrm{n}=30), 2(7 \%)$ underwent an aortic event.

Because the size of the ascending aorta was shown to be an important risk factor for aortic events, an analysis of the variables related to size of the ascending aorta was performed. It showed that for each 10 years of age, the indexed size of the ascending aorta increased by $0.11 \pm 3.9 \mathrm{~cm} / \mathrm{m}^{2}(P<.005)$. It also demonstrated, as shown in the cumulative distribution functions, that those patients undergoing aortic replacement at their original operation had average aortic sizes of $0.79 \pm$ $0.117 \mathrm{~cm} / \mathrm{m}^{2}$ larger than those who did not $(P<.0001)$.

Likely site of aortic rupture. In the examination of the evidence for aortic rupture, we attempted to deter- 


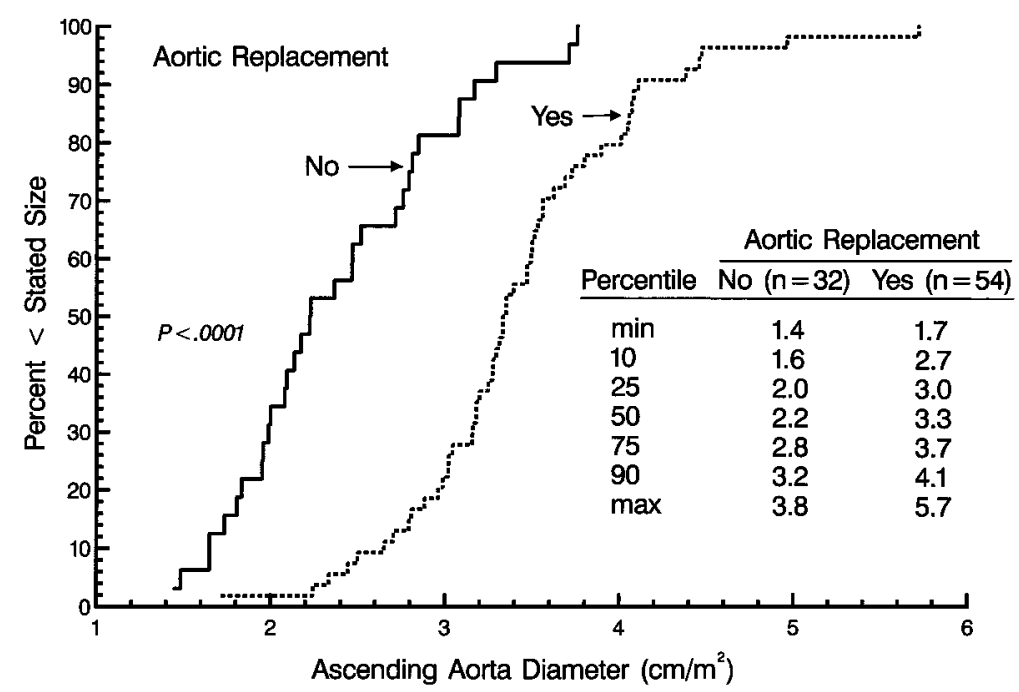

Fig 4. Cumulative frequency distribution of ascending aortic diameter indexed to BSA stratified according to whether the patient underwent a concomitant aortic repair.

Table III. Aortic events

\begin{tabular}{|c|c|c|c|c|c|}
\hline Patient & Age* & Operation & $\begin{array}{c}\text { Months between } \\
\text { operation and } \\
\text { aortic event }\end{array}$ & Likely site & Evidence of aortic event \\
\hline 1 & 51 & Bentall & 8 & Ascending & $\begin{array}{l}\text { Hypotension, low hematocrit level; aortic rupture, chest x-ray film } \\
\text { revealed widened mediastinum and left chest }\end{array}$ \\
\hline 2 & 64 & Bentall & 96 & Unknown & $\begin{array}{l}\text { Chest pain, ventricular fibrillation, aortic rupture identified in } \\
\text { emergency department }\end{array}$ \\
\hline 3 & 70 & $\mathrm{AA}+\mathrm{AVR}$ & 19 & Descending & 6-cm descending aorta identified at emergency operation \\
\hline 4 & 69 & $\mathrm{AA}+\mathrm{AVR}$ & 19 & Unknown & Aortic rupture according to attending physician \\
\hline 5 & 78 & $\mathrm{AA}+\mathrm{AVR}$ & 36 & Descending & Arch aneurysm identified at reoperation \\
\hline 6 & 74 & $\mathrm{AA}+\mathrm{AVR}$ & 73 & Descending & Ruptured descending aortic aneurysm according to family \\
\hline 7 & 73 & $\mathrm{AA}+\mathrm{AVR}$ & 84 & Descending & Ruptured thoracic aneurysm \\
\hline 8 & 70 & $\mathrm{AA}+\mathrm{AVR}$ & 84 & Descending & Known 6-cm descending aorta, thoracoabdominal rupture \\
\hline 9 & 68 & AVR & 2 & Ascending & Ascending aortic aneurysm rupture during preparation for operation \\
\hline 10 & 71 & AVR & 4 & Ascending & Chest pain, aortic rupture seen on $\mathrm{x}$-ray film \\
\hline 11 & 73 & AVR & 22 & Ascending & Ascending aneurysm according to hospital records \\
\hline 12 & 65 & AVR & 24 & Ascending & Aortic rupture just above valve according to autopsy report \\
\hline 13 & 77 & AVR & 60 & Ascending & Ascending aortic rupture according to family \\
\hline 14 & 73 & AVR & 87 & Unknown & Known aneurysmal ascending aorta, aortic rupture according to family \\
\hline 15 & 77 & $\mathrm{AVR}+\mathrm{CABG}$ & 51 & Descending & Aortic rupture according to family \\
\hline
\end{tabular}

$A A$, Aortic aneurysm; $A V R$, aortic valve replacement; $C A B G$, coronary artery bypass grafting.

*Age at operation.

mine the likely site of the rupture on the basis of the available data (Table III). In women who did not have ascending aortic operations, 5 (71\%) of 7 ruptures likely occurred in the ascending aorta, $1(14 \%)$ in the descending aorta, and $1(14 \%)$ at an unknown site. In contrast, among women who had undergone ascending aortic operations, 5 (62\%) of 8 ruptures likely occurred in the descending aorta, $1(12 \%)$ in the ascending aorta, and $2(25 \%)$ at an unknown site.

\section{Discussion}

Principal findings. This study was undertaken to investigate the outcome of women undergoing surgical intervention for severe aortic regurgitation, looking specifically at concomitant aortic pathology. The reason to focus on the aorta was the provocative data from Klodas and colleagues, ${ }^{3}$ who found women had a much worse survival after operations for isolated aortic regurgitation than did men or age-matched controls. 
The data pointed to aortic pathology as a possible explanation for reduced survival. An aortic aneurysm was present in $51 \%$ of the women compared with $25 \%$ of the men, yet a similar percentage of men and women underwent aortic root replacement. Late fatal aortic rupture or dissection occurred in $17 \%$ of the women versus $2 \%$ of the men. ${ }^{3}$

In our series most of the valves were morphologically normal, with aortic enlargement the likely cause of the aortic regurgitation. No valve-sparing operations were performed. This reflects the calendar years of the study and perhaps reflects that the surgical focus was primarily on aortic regurgitation and not aortic enlargement.

Aneurysmal changes of the ascending aorta were present in our study in $58 \%$ of the patients as defined by the surgeon, yet $38 \%$ of the patients not having ascending replacements had aortas that measured $4 \mathrm{~cm}$ or greater. This group was at particularly high risk, with $32 \%$ experiencing an aortic event, $71 \%$ of these being in the ascending aorta. The risk was most strongly associated with size indexed to the patient's size and not absolute aortic size.

From our data, $2.4 \mathrm{~cm} / \mathrm{m}^{2}$ or greater than $4.0 \mathrm{~cm}$ appears to be a reasonable threshold to consider aortic replacement in this group of patients. It is important to remember that the risk of aortic events is also related to age and is increased at similar aortic sizes in older patients. The risks of replacement will need to be balanced against the risks of future events.

General discussion. Why is there such heterogeneity in the threshold for aortic replacement in this series? One reason may have been concern about the increased risks of adding an aortic replacement to the valve procedure. More likely is the general lack of consensus in the surgical literature of the appropriate size for aortic replacement in aneurysmal disease. For example, the Ad Hoc Committee of Reporting Standards, Society for Vascular Surgery, has recommended defining the presence of an aneurysm when it is $50 \%$ larger than the normal size. ${ }^{13}$ The normal size of the ascending aorta in this report was based on a 1949 radiographic study of aortic dimension. More recent literature has recommended replacement when the ascending aorta is larger than 5.5 to $6.0 \mathrm{~cm} .^{6,14}$ Depending on the criteria used, less than $25 \%$ to over $75 \%$ of the patients in this study would have had aortic replacement. In these publications there was no recommendation to adjust dimension criteria to the patient's size, age, sex, or aortic pathology during valve or coronary procedures.

In a similar series from Japan of 86 patients with severe aortic regurgitation Natsuaki and colleagues ${ }^{15}$ found a 59\% 10-year survival and $75 \%$ freedom from aortic events in patients with ascending aortas of greater than $4.0 \mathrm{~cm}$ at the time of valve replacement. Aortoplasty appeared to be protective. In this study the average BSA was $1.6 \mathrm{~m}^{2}$. In the group with the aortic dimension/BSA ratio of less than $2.0 \mathrm{~cm} / \mathrm{m}^{2}$, there was one late death and no complications compared with the group with a ratio of greater than 2.9 in which there were 10 aortic complications and 9 late deaths. Thus, the ratio for aortic replacement of $2.4 \mathrm{~cm} / \mathrm{m}^{2}$ as determined in our article coincides with the $2.5 \mathrm{~cm} / \mathrm{m}^{2}(4.0$ $\mathrm{cm}$ ) as recommended in Natsuaki's article.

Is the risk of rupture found in women only a size issue, or is there a sex-based predilection to aortic enlargement, especially with aging? A recent study highlights sex differences in thoracic aortic aneurysm occurrence and rupture risk. A population-based cohort study from Olmsted County, Minnesota, found that the incidence of thoracic aortic aneurysm was the same for men and women, but women had similar sized aneurysms (4.9 $\mathrm{cm}$ on average) much later in life: 63 years for men versus 76 years for women. Of the ruptures that occurred, $79 \%$ were in women, with a 5-year rupture risk of $33 \%$ versus $9 \%$ for men. ${ }^{16}$ The reason for this increased rupture risk associated with older age in women is unknown. One possible explanation is that the standard size criteria for intervening may not be neutral to sex, and if indexed to BSA, women's aortic sizes would reach the threshold for intervention at a smaller absolute size. We now know from a recently published study that the aortic enlargement associated with bicuspid valve disease is related to severe degenerative changes in the aortic wall and not the valve disease. ${ }^{17}$ Baron and Galea ${ }^{18}$ have found that the media/ intima ratio of collagen and elastin content of the carotid artery decreases in postmenopausal women, suggesting that wall structure and strength may deteriorate with age. How these findings, aging, and the hormonal state of postmenopausal women affect aortic wall structure and composition requires further study.

Limitations. The study is retrospective in nature, and the size criteria for defining aneurysm disease were not uniform. This fact, however, allowed us to investigate the outcome of patients who did and did not have aortic replacement yet had similar sized ascending aortas. Determination of the exact cause of death was problematic with the limited number of autopsies. Detailed interviews with patients' families and physicians strongly support the designation of aortic rupture as the cause of death but cannot prove it. Similarly, the site of rupture is inferred from the clinical data and is labeled as a likely site of rupture in the article to highlight this limitation. Without a direct comparison with a similar group of men, the effect of sex on outcome remains unclear. 
Clinical inferences. The data suggest that our current size criteria for aortic replacement are too conservative in women. As aortic operation has become increasingly refined and safe, liberalizing the size criteria for replacement is appropriate and potentially life-saving. Cohn has recommended that during aortic valve replacement for aortic stenosis, moderately enlarged $(4.5 \mathrm{~cm})$ aortas should be replaced. ${ }^{19}$ Because dimension is the most common criteria used, we advocate normalizing to BSA and using 2.4 to 2.5 $\mathrm{cm} / \mathrm{m}^{2}$ as the threshold to consider intervention when operating on aortic valve pathology. Recognizing the abnormal aortic wall pathology in patients with a bicuspid aortic valve supports an aggressive approach in these patients. Age appears to be an important risk factor for future events. Whether sex itself is a risk and whether intervention is required in an asymptomatic woman with a normally functioning aortic valve but an aorta around $2.4 \mathrm{~cm} / \mathrm{m}^{2}$ requires further study. Finally, postoperative radiographic surveillance of the remaining aorta is imperative as ascending aortic replacement reduces but does not eliminate the risk of future aortic events.

We thank Kris Arheart, EdD, for biostatistical assistance; Karen Mrazeck for data collection and patient follow-up; and Lucinda Mitchin for manuscript preparation.

\section{REFERENCES}

1. Myers WO, Blackstone EH, Davis K, Foster ED, Kaiser GC. CASS Registry: long term surgical survival. J Am Coll Cardiol 1999;33:488-98.

2. Kubo SH, Naftel DC, Mills RM, O'Donnell J, Rodeheffer RJ, Cintron GB, et al. Risk factors for late rejection after heart transplantation: a multi-institutional, multivariable analysis. J Heart Lung Transplant 1995;14:409-18.

3. Klodas E, Enriquez-Sarano M, Tajik J, Mullany CJ, Bailey KR, Seward JB. Surgery for aortic regurgitation in women: contrasting indication and outcomes compared with men. Circulation 1996;94:2472-8.

4. Weyman AE. Principles and practices of echocardiography. Philadelphia: Lea \& Febiger; 1994.

5. Mohr-Kahaly S, Erbel R. Advantages of biplane and multiplane transesophageal echocardiography for morphology of the aorta. Am J Cardiac Imaging 1995;9:115-20.

6. Kirklin JW, Barratt-Boyes BG. Cardiac surgery. 2nd ed. Anatomy, dimensions, and terminology. New York: Churchill Livingstone; 1993. p. 3-60.

7. Kaplan EL, Meier P. Nonparametric estimation from incomplete observations. J Am Stat Assoc 1958;53:457-81.

8. Blackstone EH, Naftel DC, Turner ME Jr. The decomposition of time-varying hazard into phases, each incorporating a separate stream of concomitant information. J Am Stat Assoc 1986;81:615-24.

9. David HA, Moeschberger ML. The theory of competing risks. New York: Macmillan; 1978. p. 45-56
10. Grunkemeier GL, Anderson RP, Miller C, Starr A. Time-related analysis of nonfatal heart valve complications: cumulative incidence (actual) versus Kaplan-Meier (actuarial). Circulation 1997;96:II-70-3

11. Kalbfleisch JD, Prentice RL. The statistical analysis of failure time data. New York: John Wiley; 1980. p. 163-88.

12. Baskerville JC, Toogood JH. Guided regression modeling for prediction and exploration of structure with many explanatory variables. Technometrics 1982;24:9-17.

13. Johnston KW, Rutherford RB, Tilson MD, Shah DM, Hollier L, Stanley JC. Suggested standards for reporting on arterial aneurysms. Subcommittee on Reporting Standards for Arterial Aneurysms, Ad Hoc Committee on Reporting Standards, Society for Vascular Surgery and North American Chapter, International Society for Cardiovascular Surgery. J Vasc Surg 1991;13:452-8.

14. Coady MA, Rizzo JA, Hammond GL, Mandapati D, Darr U, Kopf GS, et al. What is the appropriate size criterion for resection of thoracic aortic aneurysm? J Thorac Cardiovasc Surg 1997;113:476-91.

15. Natsuaki M, Itoh T, Rikitake K, Okazaki Y, Naiton K. Aortic complications after aortic valve replacement in patients with dilated ascending aorta and aortic regurgitation. J Heart Valve Dis 1998;7:504-9.

16. Clouse WD, Hallett JW Jr, Schaff HV, Gayari MM, Ilstrup DM, Melton LJ. Improved prognosis of thoracic aortic aneurysms. JAMA 1998;280:1926-9.

17. De Sa M, Moshkovitz Y, Butany J, David TE. Histologic abnormalities of the ascending aorta and pulmonary trunk in patients with bicuspid aortic valve disease: clinical relevance to the Ross procedure. J Thorac Cardiovasc Surg 1999;118:588-96.

18. Baron YM, Galea MB. Carotid artery wall thickness in women treated with hormone replacement therapy. Maturitas 1997;27:47-53.

19. Cohn LH, Risso RJ, Adams DH, Aranki SF, Couper GS, Beckel $\mathrm{N}$, et al. Reduced mortality and morbidity for ascending aortic aneurysm resection regardless of cause. Ann Thorac Surg 1996;62:463-8.

\section{Discussion}

Robert J. Rizzo (Boston, Mass). Dr McDonald and her coauthors direct our attention to the problem of late aortic rupture after aortic valve replacement for aortic regurgitation in women. Dr McDonald, you report a 25\% incidence of aortic rupture at 10 years in this group. You also correlate ascending aortic diameter to the risk of aortic rupture but not specifically to the risk of ascending aortic rupture, which would be more useful. I have tried to extract this ascending aortic rupture event rate from the data in the article.

In patients who had an ascending aortic diameter of more than $5.0 \mathrm{~cm}$ and did not have aortic replacement, $3(60 \%)$ of 5 patients had ascending aortic rupture. If the ascending aortic diameter was between 4.0 and $5.0 \mathrm{~cm}$ and not replaced, 2 $(14 \%)$ of 14 had ascending aortic rupture. If the aortic diameter was less than $4.0 \mathrm{~cm}$ and not replaced, none of the patients experienced a rupture. Interestingly, if the aortic diameter was greater than $4.0 \mathrm{~cm}$ and was replaced, $2(3 \%)$ of 58 patients still had ascending aortic rupture. Clearly, your data show that the risk of ascending aortic rupture after aortic valve replacement rises with increasing ascending aortic 
diameter and is decreased by replacement of the dilated aorta but not eliminated.

I agree with your conclusions that the threshold for aortic replacement should be lower for patients expected to have a normally smaller aorta, which in most patients are the small, young, or female patients. The threshold for ascending aortic replacement should also be lower for patients in whom the chest is opened for other cardiac procedures in which the dilated aorta may not handle manipulation and suturing very well, leading to trouble. Thus, it is convenient for both the patient and the surgeon to replace the dilated aorta to prevent this later trouble. I also agree strongly that any patient with a history of a dilated aorta, whether repaired or not, should have careful follow-up to watch for progression of aortic disease and allow elective repair, and this follow-up should include both the thoracic and abdominal aorta.

My questions are as follows. First, how many of the patients in this study had the diagnosis of aortic rupture confirmed by autopsy versus by clinical or radiographic signs versus by merely having sudden death? Two, why was there rupture in the ascending aorta despite previous ascending aortic replacement, and how can this be prevented? Three, is the diameter of the ascending aorta that you currently use as your threshold for ascending aortic replacement in women after aortic valve replacement, which you have described at the end here, different for patients with aortic valve stenosis versus regurgitation, and is it different for men?
Appendix Table I. Characteristics of women with aortic regurgitation

\begin{tabular}{lrr}
\hline Characteristic & No. & $\%$ \\
\hline Cardiac morbidity & & \\
LV dysfunction by echocardiography & & \\
$\quad$ None & 60 & 55 \\
Mild & 16 & 15 \\
$\quad$ Moderate & 21 & 19 \\
$\quad$ Moderate-severe & 7 & 6 \\
$\quad$ Severe & 5 & 5 \\
NYHA class at presentation & & \\
I & 10 & 9 \\
II & 29 & 27 \\
III & 26 & 24 \\
IV & 44 & 40 \\
Coronary disease $\geq 50 \%$ & & \\
$\quad$ Left main & 3 & 3 \\
LAD & 17 & 16 \\
Circumflex & 13 & 12 \\
RCA & 17 & 16 \\
Anginal symptoms & 22 & 21 \\
Atrial fibrillation & 16 & 15 \\
Preoperative bundle branch block & 9 & 8 \\
Noncardiac comorbidity & & \\
Smoker (ever) & 40 & 38 \\
Peripheral vascular disease & 8 & 7 \\
Chronic lung disease & 6 & 6 \\
\hline
\end{tabular}

$L V$, Left ventricular; $L A D$, left anterior descending coronary artery system; $R C A$, right coronary artery system; NYHA, New York Heart Association.

Appendix Table II. Diameter of aorta at various levels from preoperative echocardiograms

\begin{tabular}{|c|c|c|c|c|c|c|c|c|}
\hline \multirow[b]{2}{*}{ Aortic level } & \multicolumn{8}{|c|}{ Percentile } \\
\hline & No. & Minimum & 10 & 25 & 50 & 75 & 90 & Махітит \\
\hline \multicolumn{9}{|l|}{ LV-aortic juncture } \\
\hline $\mathrm{cm}$ & 83 & 1.7 & 1.9 & 2.1 & 2.2 & 2.5 & 2.8 & 4.6 \\
\hline $\mathrm{cm} \cdot \mathrm{m}^{-2}$ & 81 & 0.97 & 1.12 & 1.22 & 1.34 & 1.48 & 1.63 & 2.42 \\
\hline \multicolumn{9}{|l|}{ Sinuses of Valsalva } \\
\hline $\mathrm{cm}$ & 85 & 2.3 & 2.8 & 3.1 & 3.5 & 4.1 & 4.8 & 6.5 \\
\hline $\mathrm{cm} \cdot \mathrm{m}^{-2}$ & 82 & 1.30 & 1.66 & 1.81 & 2.08 & 2.36 & 3.02 & 3.32 \\
\hline \multicolumn{9}{|l|}{ Sinotubular junction } \\
\hline $\mathrm{cm}$ & 103 & 2.3 & 3.0 & 3.3 & 3.8 & 4.6 & 5.4 & 7.4 \\
\hline $\mathrm{cm} \cdot \mathrm{m}^{-2}$ & 100 & 1.36 & 1.75 & 1.95 & 2.30 & 2.73 & 3.09 & 4.17 \\
\hline \multicolumn{9}{|l|}{ Ascending aorta } \\
\hline $\mathrm{cm}$ & 89 & 2.3 & 3.1 & 4.1 & 5.3 & 6.0 & 7.2 & 8.5 \\
\hline $\mathrm{cm} \cdot \mathrm{m}^{-2}$ & 86 & 1.45 & 1.95 & 2.44 & 3.12 & 3.51 & 4.06 & 5.72 \\
\hline \multicolumn{9}{|c|}{ Predicted normal ascending aorta* } \\
\hline $\mathrm{cm}$ & 106 & 2.2 & 2.3 & 2.4 & 2.4 & 2.5 & 2.6 & 2.8 \\
\hline $\mathrm{cm} \cdot \mathrm{m}^{-2}$ & 106 & 1.23 & 1.35 & 1.39 & 1.44 & 1.49 & 1.56 & 1.60 \\
\hline$Z$-value for ascending aorta $\dagger$ & 86 & -0.2 & 2.2 & 5.2 & 9.5 & 12 & 15 & 20 \\
\hline \multicolumn{9}{|l|}{ Transverse arch } \\
\hline $\mathrm{cm}$ & 57 & 2.1 & 2.5 & 2.7 & 3.0 & 3.5 & 3.7 & 4.8 \\
\hline $\mathrm{cm} \cdot \mathrm{m}^{-2}$ & 55 & 1.22 & 1.37 & 1.56 & 1.75 & 2.07 & 2.38 & 3.36 \\
\hline \multicolumn{9}{|l|}{ Proximal descending thoracic } \\
\hline $\mathrm{cm}$ & 52 & 1.6 & 2.0 & 2.3 & 2.6 & 3.1 & 4.5 & 6.3 \\
\hline $\mathrm{cm} \cdot \mathrm{m}^{-2}$ & 50 & 0.72 & 1.06 & 1.28 & 1.58 & 1.88 & 2.35 & 3.75 \\
\hline
\end{tabular}

Both direct values (in centimeters) and values indexed to BSA (in centimeters per square meter) are shown. $L V$, Left ventricle.

* Predicted mean normal values on the basis of BSA.

$\dagger$ Number of SDs by which women deviated from the mean normal value. 
Appendix Table III. Variables examined in multivariable analyses

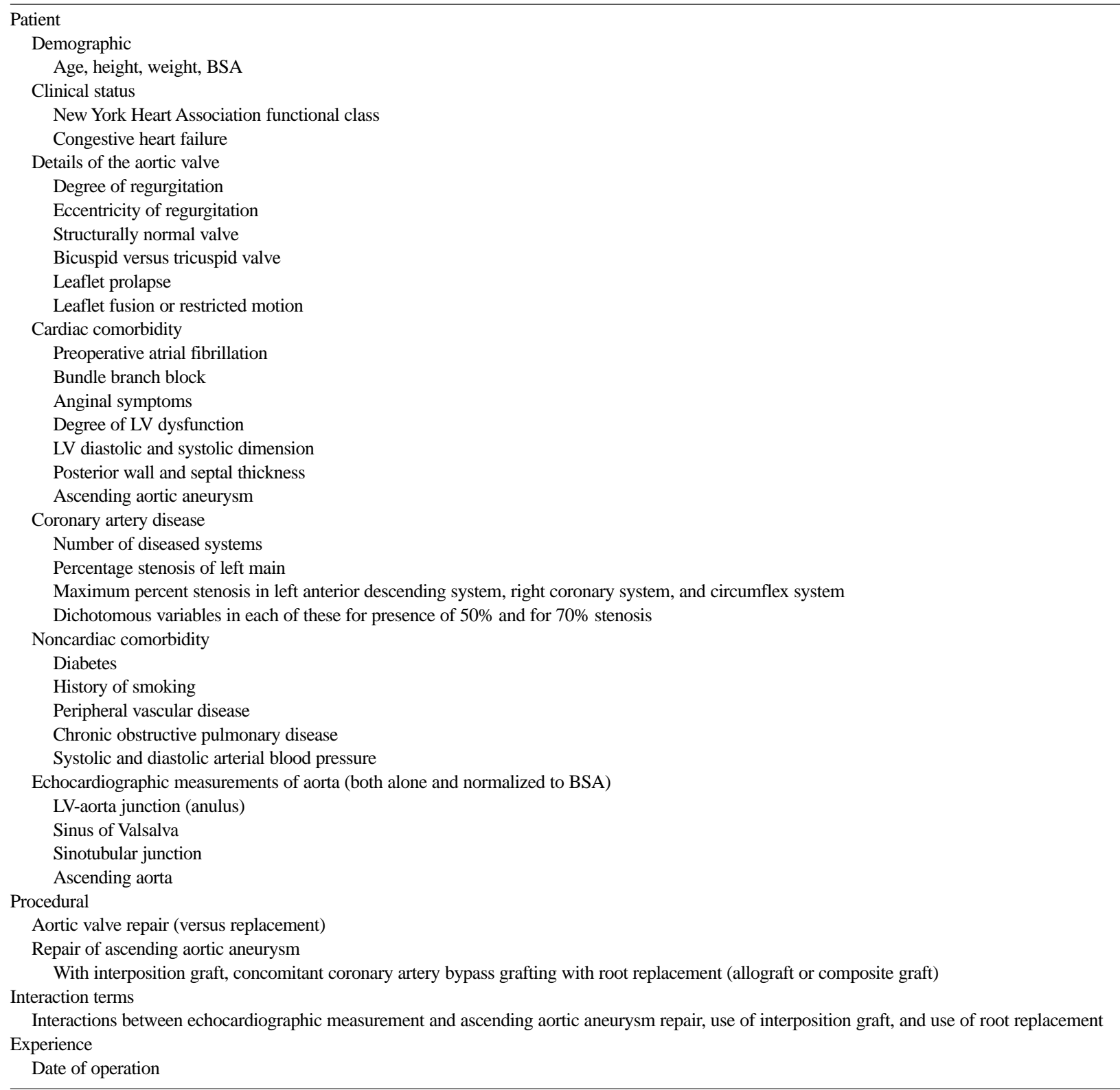

$L V$, Left ventricular.

Dr McDonald. I thank Dr Rizzo for reviewing this article. To answer the first question, we did an extensive review of each death. Although we had only one autopsy confirmation, we investigated every death certificate and were confident that we had sorted out people with sudden cardiac deaths, of whom there were 8 , versus those dying suddenly from aortic rupture.

In answer to your second question, some of the ascending aortic ruptures were late technical complications. For example, one patient died of a ruptured pseudoaneurysm. We found that women undergoing isolated valve replacement experienced early deaths, being primarily from ascending aortic rupture, whereas those undergoing an aortic operation experienced later deaths, mainly in the descending aorta. We currently do not have enough information on the preoperative aortic pathology in the cause of aortic rupture to identify a mechanism for these findings. However, we believe that the ascending aorta should be considered for replacement at the time of the operation, and 
Appendix Table IV. Univariable comparisons of survival (actuarial method)

\begin{tabular}{|c|c|c|c|c|c|c|c|c|c|c|c|}
\hline \multirow[b]{3}{*}{ Risk factors } & \multirow[b]{3}{*}{ No. } & \multicolumn{9}{|c|}{ Overall survival } & \multirow[b]{3}{*}{$\mathrm{P}$ value* } \\
\hline & & \multicolumn{3}{|c|}{$1 y$} & \multicolumn{3}{|c|}{$5 y$} & \multicolumn{3}{|c|}{$10 y$} & \\
\hline & & $\%$ & $C L$ & At riskt & $\%$ & $C L$ & At risk & $\%$ & $C L$ & At risk & \\
\hline Age (y) & & & & & & & & & & & .02 \\
\hline$<55$ & 34 & 94 & $88-97$ & 31 & 91 & $84-95$ & 23 & 67 & $52-79$ & 1 & \\
\hline $55-70$ & 36 & 86 & $79-91$ & 31 & 80 & $72-86$ & 16 & 56 & $43-68$ & 3 & \\
\hline$>70$ & 39 & 95 & $90-97$ & 37 & 68 & $59-75$ & 19 & 19 & $8-34$ & 0 & \\
\hline History of smoking $\ddagger$ & & & & & & & & & & & .02 \\
\hline No & 65 & 97 & $94-98$ & 63 & 85 & $80-90$ & 38 & 53 & $43-64$ & 3 & \\
\hline Yes & 40 & 82 & $76-88$ & 33 & 65 & $56-72$ & 16 & 37 & $26-50$ & 0 & \\
\hline Preoperative atrial fibrillation & & & & & & & & & & & .2 \\
\hline No & 93 & 92 & $89-95$ & 85 & 79 & $74-83$ & 49 & 57 & $49-64$ & 3 & \\
\hline Yes & 16 & 88 & $77-94$ & 14 & 73 & $59-83$ & 9 & 18 & $7-41$ & 1 & \\
\hline Left ventricular dysfunction & & & & & & & & & & & .3 \\
\hline None & 66 & 94 & $90-96$ & 61 & 81 & $75-86$ & & 60 & $49-70$ & 2 & \\
\hline Mild & 24 & 88 & $79-93$ & 21 & 74 & $63-82$ & 16 & 40 & $28-54$ & 2 & \\
\hline Moderate & 11 & 100 & & 11 & 81 & $66-90$ & 6 & 27 & $11-53$ & 0 & \\
\hline Severe & 8 & 75 & $57-87$ & 6 & 75 & $57-87$ & 3 & 38 & $15-67$ & 0 & \\
\hline Aortic aneurysm repair & & & & & & & & & & & .1 \\
\hline None & 50 & 90 & $85-94$ & 45 & 76 & $69-82$ & 26 & 44 & $33-55$ & 3 & \\
\hline Interposition graft & 28 & 96 & $91-99$ & 27 & 73 & $61-81$ & 12 & & & 0 & \\
\hline Root replacement & 31 & 90 & $83-94$ & 27 & 86 & $79-92$ & 20 & 74 & $62-82$ & 1 & \\
\hline
\end{tabular}

*Log rank.

$\dagger$ Number remaining at risk beyond this time interval.

†Unknown in 4.

the descending thoracic aorta needs to be monitored because of incomplete protection against future events.

The final question is about indications for aortic replacement in women undergoing a median sternotomy for either aortic stenosis or coronary grafting. In brief, we do not know the answer to this, and we do not know whether this is a phenomenon unique to the female sex or caused by the aortic regurgitation. My recommendation would be that surgeons consider replacing the aorta when it is approaching $2.4 \mathrm{~cm} / \mathrm{m}^{2}$, regardless of the indication for an operation. Further studies are needed to support this recommendation.

\section{Online-www.aats.org}

Now you can get The Journal of Thoracic and Cardiovascular Surgery online. The Journal online brings you faster delivery time, easy searching of current and back issues, links to PubMed, AATS, WTSA, and other important sites, and more. Visit the Journal online today.

\section{Receive tables of contents by e-mail}

To receive the tables of contents by e-mail, sign up through our Web site at http://www.mosby.com/jtcvs. Choose E-mail Notification. Simply type your e-mail address in the box and click the Subscribe button.

Alternatively, you may send an e-mail message to majordomo@mosby.com. Leave the subject line blank and type the following as the body of your message: subscribe jtcvs_toc.

You will receive an e-mail to confirm that you have been added to the mailing list. Note that table of contents e-mails will be sent out when a new issue is posted to the Web site. 